appeared very clearly at I ro,ooo volts, and their distance from the centre of the beam could be measured. Comparison with an assumed structure of atoms arranged in a centred cubic lattice, with the scattering electrons in each atom concentrated at its centre, failed to account for all the lines. Displacement of all the electrons from the centre along the cube diagonals in four groups of $2,8,8,8$, at distances $1 / 32,1 / 16, \mathrm{~T} / 8$, and $\mathrm{T} / 4$ respectively of the distance to the nearest atom, makes it possible to account for all the observed facts within the limit of the experimental error.

Although but a rough approximation, the excellent agreement indicates that this is a step in the right direction. Iron is given its correct valence thereby.

\title{
THE EFFECT OF X-RAYS ON THE LENGTH OF LIFE OF TRIBOLIUM CONFUSUM.'
}

\section{By Wheeler P. Davey.}

THIS is a detailed account of the work briefly described in the Physical Review, 9, 557, 558 (I9I7). A short review of the literature of the effects of X-rays on various forms of animal life is given.

The characteristics of Tribolium confusum, and the methods of manipulation employed to eliminate sources of error and the individual idiosyncrasy of the beetles are described in full.

A dose of I $5,000 \frac{\text { M.A.M. }}{25^{2}}$ at 50 kilovolts killed all beetles during administration. Doses less than $500 \frac{\text { M.A.M. }}{25^{2}}$ at 50 kilovolts were not fatal to all the beetles.

\section{THE PLIOTRON OSCILLATOR FOR THE PRODUCTION OF IARGE CURRENTS OR HIGH POTENTIAL AT HIGH FREQUENCIES. ${ }^{8}$}

\section{By William C. White.}

THE use of a pliotron of the same type of design as that recently described ${ }^{\boldsymbol{}}$ as a sort of converter to supply alternatingcurrent energy from a direct-current source is described.

${ }^{\top}$ General Electric Revrew, 20, I74-182 (I917).

'Ibid., 20, 635-637 (I917).

'Ibid., I9, 77I (I9I7) 
The principles and connections of arrangements of pliotrons for (I) the production of relatively large current and (2) for the production of relatively high voltage, both involving amounts of energy of the order of I 50 volts or less, are given.

A diagram is shown ( $\mathrm{I}$ ) to produce currents of from Io to 25 ampères from one tube at frequencies between I00,000 and $\mathrm{r}, 000,000$ cycles, for such uses as calibrating a hot-wire ammeter by direct comparison with a standard.

The nearly reverse conditions for (2) are also described and shown. Both arrangements can be operated from a direct-current source betwen 200 and 750 volts, and at 100,000 cycles a voltage of 120,000 may be obtained from one pliotron tube operating from a 500-volt, direct-current source. For higher voltages tubes may be operated in parallel.

\section{RÖNTGEN RAYS FROM SOURCES OTHER THAN THE FOCAL SPOT IN TUBES OF THE PURE ELECTRON DISCHARGE TYPE. ${ }^{10}$}

\section{By W. D. Coolidge and C. N. Moore.}

THIs paper is a detailed study by means of the pinhole camera of the amount and distribution in the Coolidge X-ray tube of radiations that might tend to blur the röntgenogram. Illustrations show the relative intensity of the X-rays given off from different parts of the target, the effect of size of bulb and of increase of voltage, and the efficacy of various hooding and other devices for intercepting such radiations. Test pictures made under comparable conditions, with and without the use of such devices, are given.

The conclusion reached is that with the present technique it is not possible for even skilled röntgenologists to distinguish between the pictures taken without and those taken with stich shielding devices. While the presence of X-rays emanating from other parts than the focal spot can be demonstrated, it is not of practical significance at this time.

${ }^{10}$ General Electric Revicue, 20, 272-281 (19r7). 